IFN Working Paper No. 743, 2008

\title{
Cross-Border Mergers \& Acquisitions Policy in Service Markets
}

Pehr-Johan Norbäck and Lars Persson 


\title{
Cross-Border Mergers \& Acquisitions
}

\author{
Policy in Service Markets
}

\author{
Pehr-Johan Norbäck and Lars Persson* \\ Research Institute of Industrial Economics (IFN)
}

April 8, 2008

\begin{abstract}
We provide facts showing that in service markets: (i) restrictions on foreign direct investment (FDI) are under reform, (ii) cross-border Mergers \& Acquisitions dominate as the entry mode of FDI, and (iii) there is often a high market concentration. Based on these facts, we present a model for analyzing cross-border M\&A policy in liberalized service markets taking into account efficiency and market power effects. Our findings suggest that a merger policy, but not a discriminatory policy towards foreigners, seems warranted. Moreover, policies ensuring competition for domestic target firms seem warranted. In this vein, harmonization of the EU takeover regulations may particularly benefit assets owners in countries with many target firms.
\end{abstract}

\footnotetext{
*We are grateful for helpful discussions with Mattias Ganslandt, Sten Nyberg and Helder Vasconcelos, and participants in the IFN 2006 Conference on Globalization of the Production of Services. Thanks also to Christina Lönnblad for improving the language. Financial support from Teknikföretagen is gratefully acknowledged. Email: pehr.johan.norback@ifn.se and lars.persson@ifn.se.
} 


\section{Introduction}

The structure of FDI has shifted towards services in the last few decades. For instance, in 1981, services accounted for about $5 \%$ of FDI inflows in the OECD countries. In 2006, the share of services in FDI flows among the OECD countries had increased to $85 \% .^{1}$ The increase in service FDI is partly driven by the increasing share of services in the economy as a whole, but is also due the large liberalization- and privatization programs in the service sector all over the world where, for instance, infrastructure services have been opened to FDI. $^{2}$

Yet, significant barriers to FDI remain in the service sector. For instance, in the EU there is currently a concern that the creation of the internal market for services is faced with obstacles, and that one such obstacle is that cross-border Mergers and Acquisitions are prevented by different national restrictions and specific rules. In 2005, Internal Market and Services Commissioner Charlie McCreevy made the following quote: Cross-border consolidation in the financial sector is weak compared to other sectors. Despite the fundamental single market principles of free movement of capital and freedom of establishment, too many obstacles stand in the way of EU financial institutions that want to go crossborder. In many instances, the business case is simply not persuasive enough. Given the fierce global competition that is emerging, we cannot afford to have 25 medium-sized markets made up of second-division champions. We want to ensure that we extract the still-to-be-realised benefits of scale that the European market of 450 million people can offer. Therefore we must tackle the obstacles identified. ${ }^{3}$

In this paper, we present a framework, built on Norbäck and Persson (2007), for studying different policy issues concerning cross-border M\&As in liberalized service markets. Our analysis takes its starting point in many of the service markets that are liberalized

\footnotetext{
${ }^{1}$ OECD International Direct Investments Statistics. Own calculations.

${ }^{2}$ See World Investment Report (2004, 2006).

3 The Commission presents an analysis of obstacles to crossborder mergers and acquisitions in the financial sector, Press Release (8.11.2005),http://ec.europa.eu/internal_market/finances/cross-sector/index_en.htm
} 
being markets with high entry barriers which will naturally be characterized by oligopolistic competition. ${ }^{4}$ Moreover, FDI in the service sector predominantly takes place through cross-border M\&As, where foreign firms acquire domestic firms, rather than making denovo entry. ${ }^{5}$ We will assume that service provision by foreign firms requires commercial presence (Mode 3 under the definition of services trade under GATS), but otherwise abstract from the issue of how FDI and cross-border M\&As differ between services and goods.

In the model, a domestic firm is initially located in the market in the host country. There are also several multinational enterprises (MNEs) located in the world market. The market in the host country will now be exposed to international competition. In a first stage, the host country set its cross-border M\&A policy. In the second stage, the MNEs might acquire the domestic firm's assets. In the third stage, firms have the option of investing in new assets. Some MNEs may not be able to recover the investment costs associated with greenfield entry and will then not enter. Finally, firms compete in oligopoly fashion in the service market. We develop a simple graphical solution to the model which we use to illustrate the results. In the Appendix, we also provide a Linear-Quadratic Cournot Model, with asset complementarities and endogenous investment, which can be used to evaluate different policies in more detail.

In the policy debate, the effects of cross-border M\&As on the host economy are a greatly discussed issue. ${ }^{6}$ Despite the welcoming attitude towards inward FDI among countries liberalizing their service markets, some concerns are raised about the impact of cross-

${ }^{4}$ This is the case in the telecom, energy and banking industries, for instance.

${ }^{5}$ See World Investment Report $(2004,2006)$.

${ }^{6}$ For instance, the rumors about a takeover bid of the French dairy producer Danone by the American company PepsiCo provoked an outcry in the French political arena, some politicians swearing to protect this French company from any foreign takeover. A few weeks later, the French government officially proposed to shield ten "strategic" industries, including biotechnologies, secure information systems, casinos and the production of vaccines, from foreign acquisitions.

See, for instance, International Herald Tribune, Business, "Bank chief in Italy off EU hook?" Saturday, September 17, 2005. 
border mergers and acquisitions (M\&As). One such concern is that strong foreign entrants can acquire domestic firms at "too low" a price. There is also a concern that, in contrast to greenfield entry, cross-border M\&As are driven by market power reasons and do not increase the productive capacity and might lead to lower consumer welfare and layoffs.

To address this issue, we first study the impact of a discriminatory cross-border merger law. Our first result is then to show that discriminatory cross-border merger law risks being counterproductive by blocking cross-border M\&As associated with complementarities that would benefit both domestic consumers and domestic owners. We also show that there is a limit to the possibility for market power driven cross-border M\&As, since they may trigger greenfield entry and expansion by rival firms. These findings thus suggest that a merger law discriminating against cross-border acquisition does not seem generally motivated, since it may hamper an efficient structural change of domestic industry; rather a merger law blocking foreign acquisitions driven by market power motives is to be preferred.

We then study other policies towards cross-border M\&As. In particular, we show that specific takeover regulations that increase the cost of foreign acquisitions or preferential treatment of specific buyers could be counterproductive. The reason is that these policies imply that there will be few potential buyers of domestic firms. We then show that with seller competition, the gains from an acquisition at high complementarities accrue to the foreign acquirer, in fact leaving domestic firms worse off, and may reduce total welfare. Having policies that give many potential buyers the opportunity to participate in the acquisition market therefore seems well motivated. This seems particularly relevant in the case of privatizations. Moreover, harmonization of the EU takeover regulations is, in this respect, not only beneficial for potential acquiring firms, but foremost for owners of target firms.

Another channel through which merger policy can play an important role in liberalized service markets is through the fact that incumbents who have established a strong initial position might try to protect their market from new foreign entry. Indeed, in the analysis, it is established that for sufficiently high entry costs and sufficiently concentrated service 
markets, preemptive domestic acquisitions can take place, i.e. acquisitions motivated by the desire to prevent a cross-border acquisition that would increase competition in the market. Consequently, competition authorities have an important task in monitoring these behaviors and considering preemptive domestic acquisitions.

The related theoretical literature on FDI and MNEs is surveyed in Barba Navaretti and Venables (2004). Typically, this literature does not explicitly address the question of whether entry into a foreign market is greenfield or through the acquisition of assets already in the market, or both, and its welfare implications, an issue which constitutes the focus of our study. ${ }^{7}$ There is also a small theoretical literature addressing the welfare aspects of cross-border mergers in international oligopoly markets. ${ }^{8}$ But this literature typically treats the greenfield investment alternative as cursory.

More closely related papers are Mattoo, Olarrega and Saggi (2004) and Klimenko and Saggi (2005). They study how entry mode affects welfare in markets where foreign technology transfers are possible. They find that restrictions on cross-border M\&As can be welfare enhancing in such an environment. The reason is that foreign entrants may use a more updated technology when entering greenfield than by an acquisition. However, they abstract from the competitive bidding over the domestic firm, which is central in our approach.

As stated above, the theoretical model is built on Norbäck and Persson (2007), and is also closely related to Norbäck and Persson (2005). Both these papers study welfare effects of cross-border M\&A and greenfield entry in an international oligopoly market. The first value added of this paper is that it provides facts about the service markets showing that the general set-up of those models is applicable in studies of the service market.

\footnotetext{
${ }^{7}$ See Bjorvatn (2004), Nocke and Yeaple (2007), and Norbäck and Persson (2004) for papers addressing the choice of entry mode.

8 This literature includes papers by, for example, Falvey (1998), Head and Reis (1997), Heyman, Sjöholm and Tingvall (2007), Horn and Persson (2001), Lommerud, Straume and Sorgard (2004) and Neary (2007).
} 
Moreover, in order to simplify the dialogue between researchers and policy circles, we have made the model more reader friendly and have also added an explicit policy stage that makes the model tractable for different policy analyses in a coherent way. We have also extended the Norbäck and Persson $(2005,2007)$ models by allowing for (i) the possibility that cross-border M\&As might trigger more greenfield entry, and (ii) allowing for seller competition.

In Section 2, we present facts about FDI in the service sector, on which we build our theoretical policy framework. In Section 3 the base model is described. Section 4 studies the impact on the host country of cross-border M\&A policy in liberalized service markets in terms of (i) discriminatory cross-border merger laws, (ii) local equity requirements, and (iii) foreign takeover regulations. Section 5 studies the effects of domestic merger policy in liberalized service markets and Section 6 concludes the paper.

\section{Facts about FDI in the service sector}

In this section, we will describe a number of facts about FDI in the service sector. These facts will show that FDI in services and, in particular, cross-border acquisitions in services, are important for the development of the service sector. These facts will also be used to set up a suitable theoretical framework for analyzing FDI policy in the next section, taking into account market power and efficiency effects associated with FDI.

In the last few decades, there has been a tremendous increase in FDI in the world economy. This is illustrated in Figure 2.1, which shows the stock of inward FDI relative to GDP for the world. As illustrated by the figure, FDI has increased relative to GDP over the last few decades. In fact, FDI has not only also grown faster than GDP, it has also outpaced the growth of world trade in this period. ${ }^{9}$ Thus, the importance of FDI in the world economy has increased dramatically over the last 15 years.

FDI in manufacturing has historically dominated firms' investments abroad, but the

\footnotetext{
${ }^{9}$ Se Barbaretti and Venables (2004).
} 
Inward FDI stocks

as a percentage of GDP 1981-2006

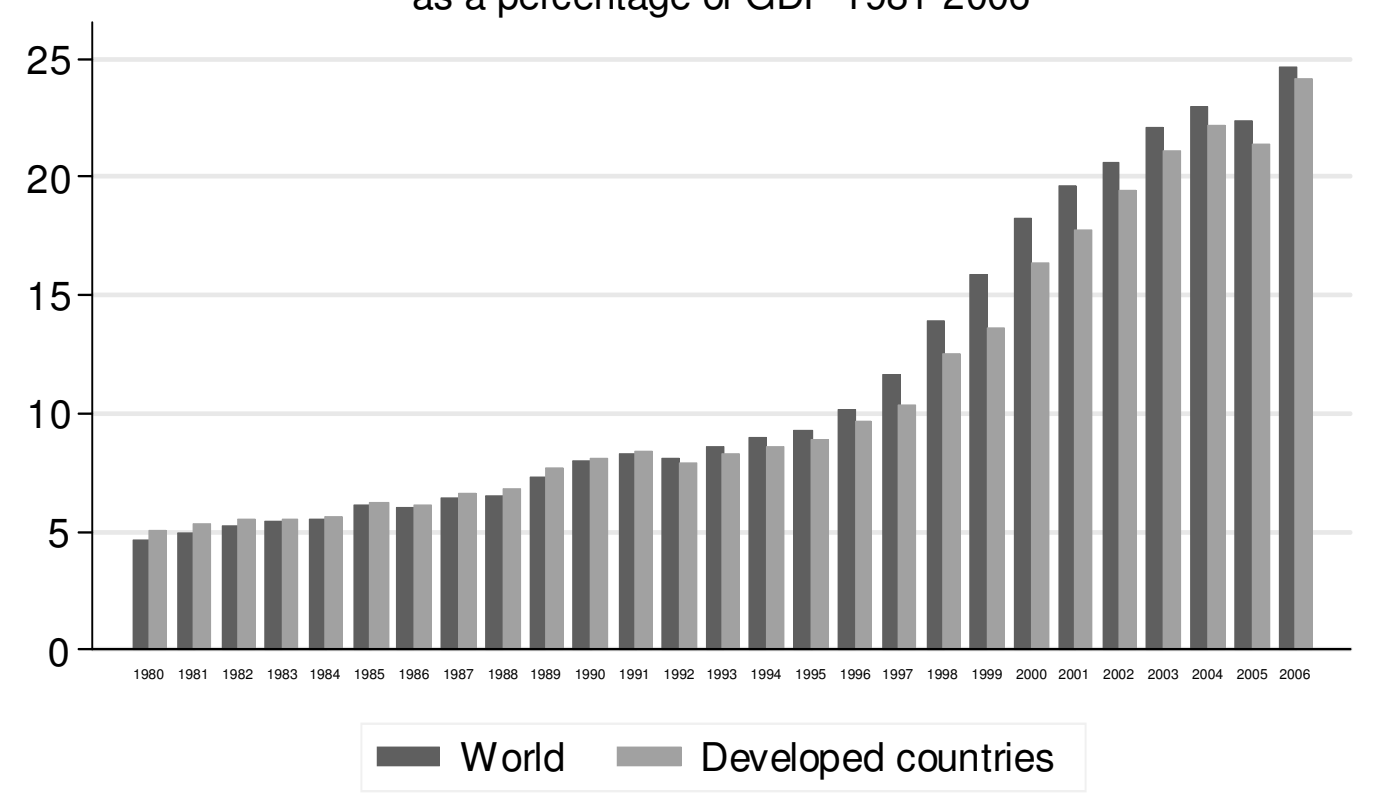

Source: Unctad

Figure 2.1: The increased importance of FDI in the world economy. 


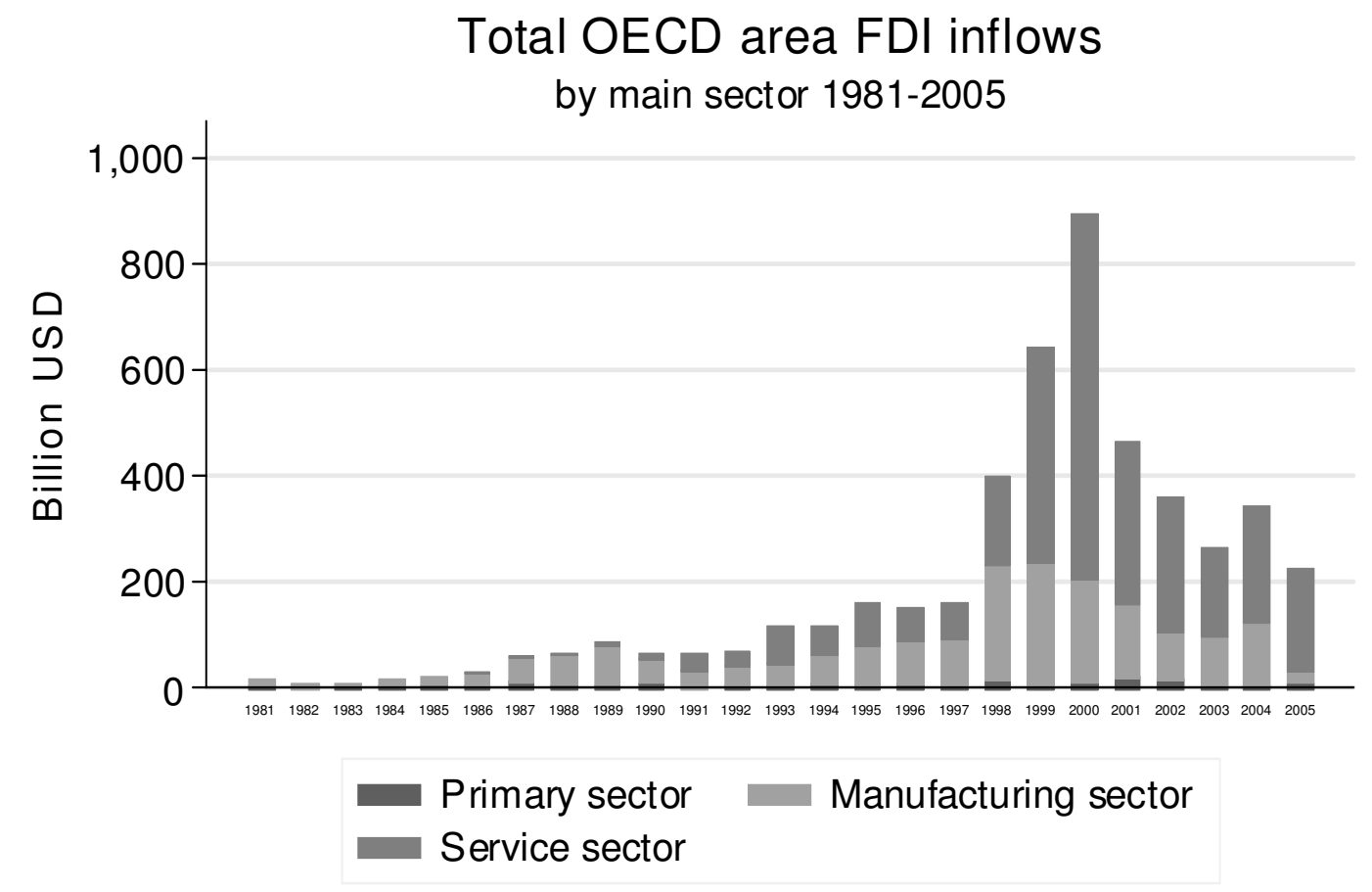

Source: OECD

Figure 2.2: Illustrating the increasing importance of FDI in services. 


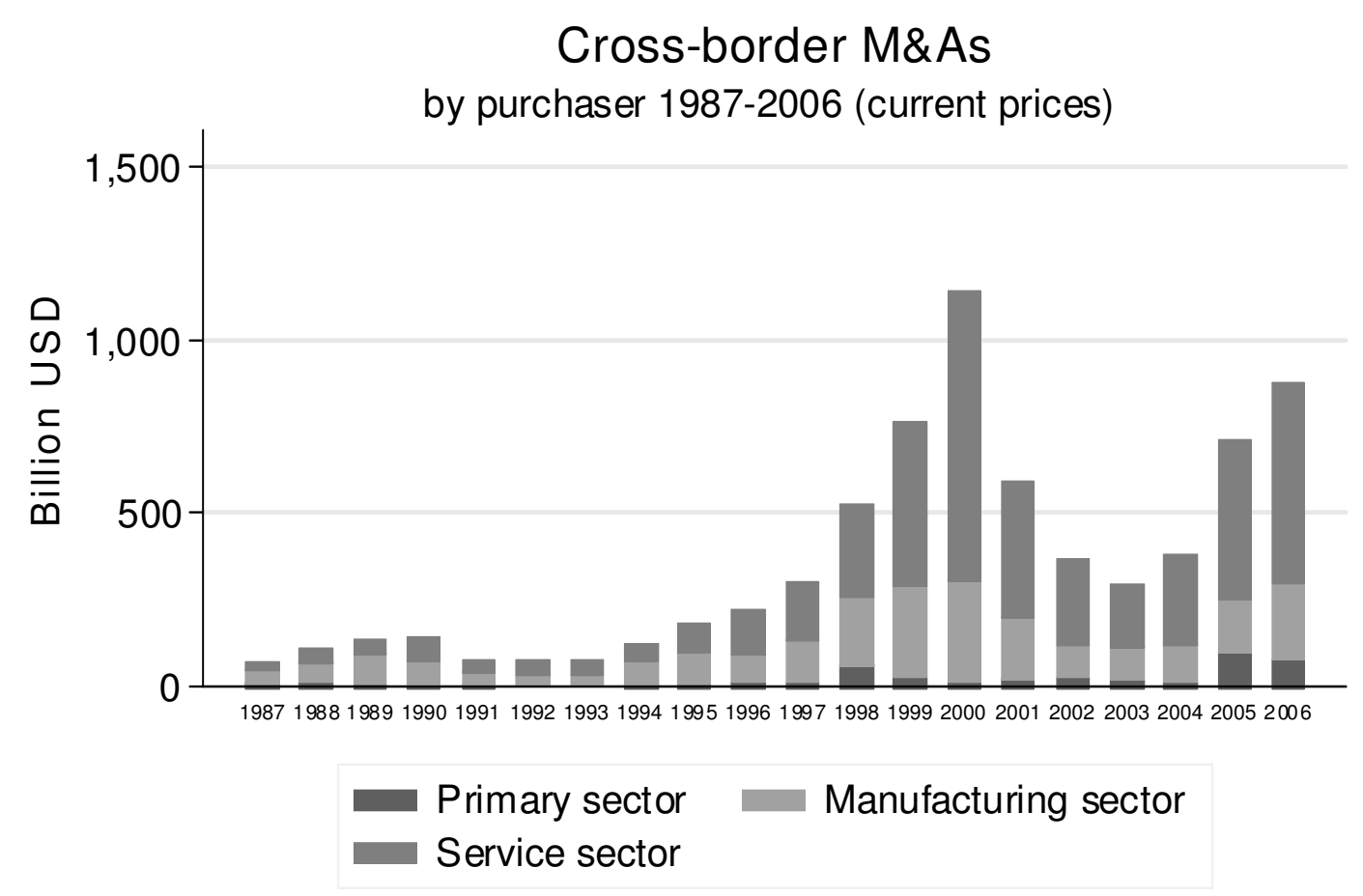

Source: Unctad

Figure 2.3: Illustrating the increased importance of services in cross-border M\&As. 
composition of FDI has shifted towards FDI in services during the last few decades. This is shown in Figure 2.2, which disaggregates FDI flows into three components: investments into the service sector, investments into the manufacturing sector and investments into the primary sector. We can note that there is a steady increase in investment flows up to the year 2000 when there was a peak in investment flows. We can also note that the share of services is steadily increasing over the period, and perhaps even more so after the downturn in the year 2000. This development mirrors increasing FDI in more traditional services such as banking, retailing and wholesale distribution, but in later years there has also been an increase in the importance of business services, and the transport and communication sectors (OECD, 2006). The increase in FDI in services is expected to continue since the service sector accounts for the largest share of economic activities in both developed and developing countries. ${ }^{10}$

What is then the preferred mode of FDI in services? As compared to manufacturing, the propensity to enter new markets through an acquisition, rather than greenfield FDI where a new venture is set up, is larger in services (WIR, 2004). For instance, in the banking industry, firms will build up business networks from scratch to a lesser extent. Rather, they will attempt to acquire existing networks from local banks, which are then developed using the MNEs' specific assets in, for instance, knowledge of risk management. In general, in acquisitions, MNEs add their firm-specific assets, such as knowledge, managerial practices or information processing, to acquired assets. This combination of assets then creates complementarities or synergies. Figure 2.3 illustrates how cross-border acquisition in services has come to dominate aggregate cross-border acquisition flows in later years. In fact, comparing Figure 2.2 and Figure 2.3 suggests that FDI being dominated by FDI in services to a very large extent reflects the increasing importance of cross-border acquisition in services. Thus, increasing cross-border mergers and acquisitions (M\&As) in

\footnotetext{
${ }^{10}$ The service share of GDP is today around $70 \%$ in developed countries and around $50 \%$ in developing countries (WIR 2004). FDI in services is increasing in importance and the largest share of FDI now takes place in this area.
} 
services have contributed to the dominance of services in FDI flows.

There is some evidence that services have become increasingly tradable across borders, making services part of the international division of labor in production networks administered by multinational firms. However, many services are inherently nontradable and hence, need to be consumed where they are produced. For instance, WIR 2004 notes that in the US, the share of sales by affiliates to foreign MNEs to the local market was $93 \%$ for services. The same numbers for worldwide sales of foreign affiliates of US multinational firms were $84 \%$ for services and $61 \%$ for manufacturing. This suggests that a FDI in services is still predominately market seeking.

Cross-border acquisitions sometimes involve very large transactions which may affect the market structure in a host country. For instance, privatization programs which have opened up for cross-border acquisitions in liberalizing countries may imply that oligopolies are created after the privatization. Therefore, cross-border acquisitions are likely to have different market power effects than greenfield entry in service sectors with considerable entry barriers. Cross-border acquisitions with very high transaction values are also more common in the service sector. To illustrate this, the inward cross-border deals with a value above USD 1.5 billion dollars during the period January 2005 to May 2006 were about twice as many in the service sector as compared to the manufacturing sector (OECD, 2006). This suggests that many service sectors are characterized by oligopolistic competition.

It is also established in the FDI literature that MNEs are typically leading firms in their respective industries, and possess firm-specific knowledge in terms of technology or knowhow of organization of production and marketing (see Barba Navaretti and Venables, 2004 and Markusen, 1995). In general, FDI is therefore associated with efficient production. Some of this knowledge may be transferred when cross-border M\&A takes place, resulting in a more productive or efficient use of the local assets.

Even though many countries have begun to liberalize investments regimes, considerable barriers to investments still exist in the service sector. WIR (2004) reports that the service sector has the largest share of restrictions to FDI. This may reflect the fears in 
host countries of adverse effects of FDI on domestic competitors or other non-economic values. As noted by WIR (2006), the size of the cross-border acquisitions in services and the impact on the subsequent market structure also imply that regulatory regimes and competition policies may be needed in order to achieve economic efficiency and create competition in the market. Thus, even if FDI in services is increasing due to liberalization, restrictions on FDI are still common in the service sector.

To summarize: (i) many liberalized service markets are inherently concentrated due to high entry barriers, (ii) technological efficiency differences between firms are likely to be large due to the fast development in these markets, and (iii) today a considerable part of direct investments in the service sector take place through cross-border acquisitions instead of de-novo entry. This raises several policy issues: would a restrictive cross-border merger policy be welfare improving by preventing market power driven cross-border mergers and triggering greenfield entry or be welfare reducing by preventing efficiency motivated cross-border mergers? Could domestic incumbents protect their service market from pro-competitive foreign entry? In the next section, we will develop a suitable theoretical framework to address these issues.

\section{The base model}

We will here present a theoretical framework model, built on Norbäck and Persson (2007), which incorporates market power and efficiency effects of FDI. We simplify the analysis by assuming that initially, there is only one domestic firm, denoted $d$, in the domestic market. The domestic firm possesses some unique domestic assets, denoted $k_{0}$, which could be a distribution system, ownership of land or permits, knowledge of the specific characteristics of the local market, locally well-known brand names, or some other strategic assets already in the market. The market is thus initially a domestic monopoly which is now opened up to FDI by $M$ symmetric foreign firms. We assume there to be domestic consumers of the service that the market supplies. Wages or other factor costs are taken as exogenously 
given and we further by assume that the service is not tradeable.

In the literature, it is argued that an acquisition is a fast way of entering a new market and getting access to local strategically important assets such as local distribution networks. Thus, one can imagine a sequence of events, modeled as a four-stage game with the following ingredients.

- In the first stage the government decides on policy towards cross-border M\&As

- In the second stage, the MNEs bid for the domestic firm, which can accept or reject the bids for acquisition.

- In the third stage, firms can invest in new assets. The number of firms investing will depend on the fixed cost of greenfield entry.

- Finally, in the fourth stage, firms interact in an oligopolistic service market, where the number of firms is sufficiently small so that the firms can affect consumer prices.

We are now set to solve the model which is done by backward induction.

\subsection{Stage 4: service market interaction}

Let the profit for firm $i$ be:

$$
\pi_{i}(\mathbf{x}, \boldsymbol{\kappa}, l)=R_{i}(\mathbf{x}, \boldsymbol{\kappa}, l)-G_{i}-F_{i}\left(\kappa_{i}\right)
$$

where $\mathbf{x}=\left(x_{d}, x_{m_{1}, \ldots,}, x_{m_{M}}\right)$ is the vector of actions taken by firms in the service market interaction in period $4, \boldsymbol{\kappa}=\left(\kappa_{d}, \kappa_{m_{1}, \ldots,}, \kappa_{m_{M}}\right)$ denotes the vector of greenfield investments in new assets in period 3 , and $l$ denotes the ownership of the domestic assets, given from the acquisition game in period 1. $R_{i}(\mathbf{x}, \boldsymbol{\kappa}, l)$ is the period-three service market profit, $G_{i}$ is a fixed cost of investment in period 3 and $F_{i}\left(\kappa_{i}\right)$ is the variable cost of investment in new assets $\kappa_{i}$ in period 3 .

Firm $i$ chooses an action $x_{i}$ to maximize its service market profit, $R_{i}\left(x_{i}, x_{-i}: \boldsymbol{\kappa}, l\right)$, where $x_{-i}$ is the set of actions taken by $i$ 's rivals. We assume there to exist a unique 
Nash-Equilibrium, $\mathbf{x}^{*}(\boldsymbol{\kappa}, l)$, defined as:

$$
R_{i}\left(x_{i}^{*}, x_{-i}^{*}: \boldsymbol{\kappa}, l\right) \geq R_{i}\left(x_{i}, x_{-i}^{*}: \boldsymbol{\kappa}, l\right), \quad \forall x_{i} \in R^{+} .
$$

From (3.2), we can define a reduced-form profit for a firm $i$, taking as given the ownership $l$ of the domestic assets $k_{0}$ and the vector of new investments $\boldsymbol{\kappa}$, as $\pi_{i}(\boldsymbol{\kappa}, l) \equiv$ $R_{i}\left(x_{i}^{*}(\boldsymbol{\kappa}, l), x_{-i}^{*}(\boldsymbol{\kappa}, l), \boldsymbol{\kappa}, l\right)-G_{i}-F_{i}\left(\kappa_{i}\right)$.

\subsection{Period 3: investments in new assets and greenfield entry}

In period 3, firm $i$ invests in new assets, $\kappa_{i}$. New investments are labeled greenfield investments for non-acquiring MNEs, and sequential investments for the acquiring MNE (if a sale occurs) and the domestic firm (if no sale occurs). We make the standard assumptions that reduced-form profit $\pi_{i}(\boldsymbol{\kappa}, l)$ decreases in the number of firms in the market. For a given number of firms in the market, the reduced-form profit $\pi_{i}(\boldsymbol{\kappa}, l)$ is decreasing in rivals' investments $\kappa_{-i}$, and is strictly concave in own investments $\kappa_{i}$ and increasing in $\kappa_{i}$ for some $\kappa_{i}$.

We then assume that the entry decisions by non-acquiring MNEs and the investment decisions by these firms and the possessor of the assets $k_{0}$ (the acquiring MNE or firm d) take place simultaneously, i.e. the number of MNEs entering greenfield $N$ and firms' investments $\kappa_{i}$ are simultaneously determined. Some MNEs may not be able to recover the investment costs associated with greenfield entry and instead set $\kappa_{E}(l)=0$.

Formally, firm $i$ makes its choice $\kappa_{i} \in R^{+}$to maximize the reduced-form profit, $\pi_{i}(\boldsymbol{\kappa}, l)$ which we rewrite as $\pi_{i}\left(\kappa_{i}, \kappa_{-i}: l\right)$, where $\kappa_{-i}$ denotes investments in new assets by $i$ 's rivals. We assume there to exist a unique Nash-Equilibrium, $\boldsymbol{\kappa}^{*}(l)$ defined from:

$$
\pi_{i}\left(\kappa_{i}^{*}, \kappa_{-i}^{*}: l\right) \geq \pi_{i}\left(\kappa_{i}, \kappa_{-i}^{*}: l\right), \quad \forall \kappa_{i} \in R^{+}
$$

The asset ownership structure $\mathbf{K}=\left(k_{d}, k_{m_{1}, \ldots}, k_{m_{M}}\right)$ then specifies the asset ownership of each firm. The first entry refers to firm d's asset holdings, the second to MNE 1's asset 
holdings, etc. There are two types of asset ownership structures: $\mathbf{K}(m)$ and $\mathbf{K}(d)$ :

$$
\begin{aligned}
\mathbf{K}(m) & =(0, \gamma k_{0}+\kappa_{A}^{*}(m), \underbrace{\kappa_{G}^{*}(m), \ldots, \kappa_{G}^{*}(m)}_{N(m)}, \underbrace{0, \ldots, 0}_{M-N(m)-1}), \\
\mathbf{K}(d) & =(k_{0}+\kappa_{d}^{*}(d), \underbrace{\kappa_{G}^{*}(d), \ldots, \kappa_{G}^{*}(d)}_{N(d)}, \underbrace{0, \ldots, 0}_{M-N(d)}) .
\end{aligned}
$$

This allows us to define $\left.\pi_{i}(l) \equiv \pi_{i}\left(\boldsymbol{\kappa}^{*}(l), l\right) \equiv \pi_{h}\left(\mathbf{x}^{*}\left(\boldsymbol{\kappa}^{*}(l)\right), \boldsymbol{\kappa}^{*}(l), l\right)\right)$ as a reduced-form profit function for firm $i$ under ownership $l$, encompassing the firms' optimal actions in period three, $\mathbf{x}^{*}$, and optimal investments in new assets in period two, $\boldsymbol{\kappa}^{*}$.

The assumption that MNEs $1,2, . . M$ are symmetric before the acquisition takes place implies that we need only distinguish between two types of ownerships; domestic ownership $(l=d)$ and foreign (MNE) ownership $(l=m)$. In (3.4), $\gamma$ is a measure of the complementarity, or synergy, between the domestic assets $k_{0}$ and MNEs' firm-specific assets when an acquisition takes place. Note that the "effective size" of the domestic assets $k_{0}$ under foreign ownership is $\gamma k_{0}$. MNEs are typically leading firms, and possess firmspecific knowledge in terms of technology or know-how of organization of production and marketing (see Barbaretti and Venables, 2004 and Markusen, 1995). Some of this knowledge may be transferred under a change of ownership, resulting in a more productive or efficient use of the local assets, $k_{0}$, which would correspond to a $\gamma$ which is larger than one. However, if $\gamma$ is less than one, an MNE is less efficient in using $k_{0}$ than the domestic firm. In what follows, we will say that such an acquisition is a technologically inefficient acquisition. Then, we will assume that an increase in the complementarity between the domestic assets and the MNEs' firm-specific assets $\gamma$ implies that the profit of the acquiring MNE $\pi_{A}(m)$ increases and the profits of the rival firms $\pi_{G}(m)$ decrease.

Definition 1: $\frac{d \pi_{A}(m)}{d \gamma}>0=\frac{d \pi_{h}(d)}{d \gamma}>\frac{d \pi_{G}(m)}{d \gamma}, h=\{d, G\}$

This definition is natural in oligopoly models, where asset holdings affect production costs, and simply states that the acquiring firm becomes more aggressive in the service market when, for instance, faced with a marginal cost reduction. 


\subsection{Period 2: Solving for the pattern of cross-border acquisitions}

We are now set to derive the equilibrium acquisition pattern. To simplify, we will then assume that greenfield entrants bear the symmetric fixed cost $G$, whereas the acquiring MNE and the domestic firm are assumed to have zero fixed costs. To further simplify the presentation, we distinguish between two cases: Low entry barriers, where fixed costs $G$ are so low that all MNEs enter the market and High entry barriers, where the fixed cost $G$ generates entry barriers so that some MNEs cannot profitably enter the market through greenfield entry.

\subsubsection{Low entry barriers}

All MNEs are assumed to enter the market in this case. Whether a cross-border acquisition will take place depends on the MNE's valuation of obtaining the domestic firm's assets and the domestic firm's reservation price of selling its assets. There are three different valuations which need to be considered:

- $v_{m m}$, referred to as the preemptive valuation, is the valuation for an MNE of obtaining $k_{0}$, when a rival MNE would otherwise obtain $k_{0}$. The first term $\pi_{A}(m)$ shows the profit when possessing $\bar{k}$. The second term $\pi_{G}(m)$ shows the profit if a rival MNE obtains $k_{0}$, in which case the MNE invests greenfield

$$
v_{m m}=\pi_{A}(m)-\pi_{G}(m) .
$$

- $v_{m d}$, referred to as the takeover valuation, is the valuation for an MNE of obtaining $k_{0}$, when the domestic firm would otherwise keep them. The second term $\pi_{G}(d)$ is the profit for an MNE of not obtaining the assets $k_{0}$. This term is different in this case, due to the change of identity of the firm that would otherwise obtain the assets

$$
v_{m d}=\pi_{A}(m)-\pi_{G}(d) .
$$


- $v_{d}$, referred to as the reservation valuation, is the profit $\pi_{d}(d)$ for the domestic firm of keeping $k_{0}$ :

$$
v_{d}=\pi_{d}(d) .
$$

A solution to the model is presented graphically in Figure 3.1. In the Appendix, we also provide a Linear-Quadratic Cournot Model, with asset complementarities and endogenous investment, which can be used to derive a parametric solution. The horizontal curve in Figure 3.1(i) shows the reservation valuation of the domestic firm $v_{d}=\pi_{d}(d)$ in (3.8). This curve does not vary with the complementarity since there is no ownership change. The upward-sloping curve $v_{m d}=\pi_{A}(m)-\pi_{G}(d)$ is an MNE's takeover valuation of the domestic firm in (3.7). Once more, note that this shows how the MNEs value the domestic firm, given that the domestic firm would otherwise remain on the market. The takeover valuation increases in the degree of complementarities since the acquirer's service market profit $\pi_{A}(m)$ will be higher the more efficient assets it has at its disposal. The other upward-sloping curve $v_{m m}=\pi_{A}(m)-\pi_{G}(m)$ is the preemptive valuation in (3.6) and shows how the MNEs value the domestic firm, given that the domestic firm would otherwise be acquired by a foreign rival. Note that the preemptive valuation $v_{m m}$ is not only driven by the benefits of obtaining a strong position in the service market as an acquirer, but there is also the preemptive motive for avoiding a weak position as a non-acquirer. This makes curve $v_{m m}$ steeper than curve $v_{m d}$. The solution to the model can now be described as follows:

When complementarities are low and $\gamma$ is below the threshold level $\gamma^{T}$, an MNE's takeover valuation is lower than the domestic firm's reservation price. This is illustrated in Figure 3.1(i) where the $v_{d}$ curve is above the $v_{m d}$ curve. Thus, the saving of fixed greenfield $\operatorname{cost} G$ and the increase in concentration associated with the acquisition is not enough to make an acquisition profitable due to the inefficient use of the domestic assets. Intuitively, if an acquisition is mainly driven by the desire to eliminate the domestic rival in order to be able to increase service market prices, this will imply that rivals in the market 


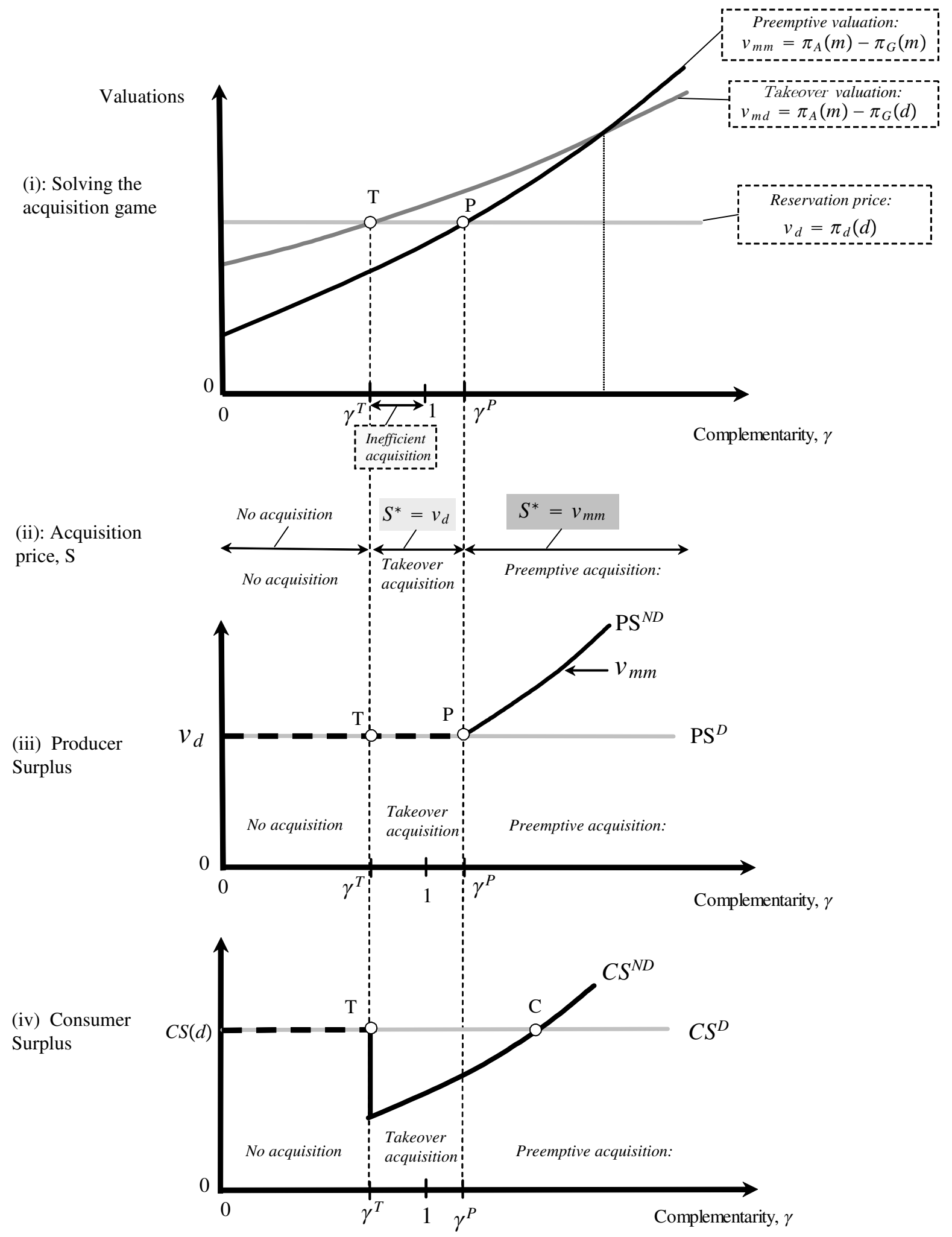

Figure 3.1: Solving the model under low entry barriers. 
will have an incentive to expand their sales and hence, the profitability of an acquisition is low.

At sufficiently high complementarities $\gamma$, however, a takeover acquisition is profitable since the takeover valuation $v_{m d}$ is higher than the reservation price $v_{d}$. This is illustrated at point $\mathrm{T}$ in Figure 3.1(i). In the region where $\gamma$ is between thresholds $\gamma^{T}$ and $\gamma^{P}$, one of the MNEs will acquire the domestic firm at a price $S^{*}$ marginally higher than $v_{d}$. Other MNEs will not try to preempt such an acquisition, since a rival MNE is better off as a non-acquirer, due to the benefit from a more concentrated market. This can be also seen in Figure 3.1(i) where the reservation price $v_{d}$ exceeds the dotted part of the locus for the preemptive valuation $v_{m m}$.

Finally, turn to the case with high levels of complementarity between MNEs' assets and domestic assets. Increasing complementarities beyond threshold $\gamma^{P}$ in Figure 3.1(i) will make a preemptive acquisition strictly profitable and the preemptive valuation $v_{m m}$ now exceeds the reservation price $v_{d}$. This is illustrated in point $\mathrm{P}$ in Figure 3.1(i). Then, paying the reservation price $v_{d}$ cannot be an equilibrium since other MNEs would strictly gain from increasing their bids above $v_{d}$. Since this implies a bidding competition over the domestic assets, we depict the locus of takeover valuation $v_{m d}$ as dotted, focusing on the locus of the preemptive valuation $v_{m m}$. As the MNEs will raise their bids, competition will drive the equilibrium sales price $S^{*}$ all the way to $v_{m m}$, where the MNEs are indifferent between buying and not buying the domestic assets.

\subsubsection{High entry barriers}

Let us now consider the situation where not all MNEs entering greenfield can cover the entry cost $G$. Thus, not all MNEs will enter the market. To indicate that the acquisition pattern may affect the number of greenfield entrants, we write profits as $\pi_{h}(N(l))$, where $N(l)$ is the number of greenfield entrants. From (3.3), greenfield entry takes place until the last greenfield entrant cannot cover its investment costs, that is, $\pi_{G}(N(l))>0$ and 
$\pi_{G}(N(l)+1) \leq 0$. The probability of successful greenfield entry $p(l)$ is then:

$$
\mathrm{p}(l)= \begin{cases}\frac{N(m)}{M-1} & \text { if } l=m \\ \frac{N(d)}{M} & \text { if } \quad l=d .\end{cases}
$$

Introducing uncertainty in greenfield entry, we then need to adjust firms' valuations of the domestic assets. These valuations now become $v_{m m}=\pi_{A}(m)-\mathrm{p}(m) \pi_{G}(m), v_{m d}=$ $\left.\pi_{A}(m)-\mathrm{p}(d) \pi_{G}(d)\right)$ and, finally, $v_{d}=\pi_{d}(d)$, where we have omitted the number of firms $N(l)$.

Several new effects appear as shown in Figure 3.2, which can be shown to be valid in the LQC model given in the Appendix. ${ }^{11}$ When complementarities are sufficiently low as shown at point $E_{1}$ in Figure 3.2(i), a cross-border M\&A can trigger greenfield entry in which case inefficient acquisitions, where $\gamma^{T}<1$, cannot occur. The reason is that the profit of the domestic target firm $\pi_{d}(N(d))$ is then always larger than the acquiring firm's profit $\pi_{A}(N(m))$ since they face the same number of competitors, i.e. $N(d)=N(m)$. Thus, a foreign acquisition cannot be profitable, $v_{d}>v_{m l}, l=m, d$ without emerging synergies. This is also illustrated in Figure 3.2(ii), where $\gamma^{T}>1 .^{12}$

Moreover, for high complementarities, a cross-border acquisition can be associated with fewer greenfield entrants being able to cover their fixed cost. The reason is that they now face a tougher competitor, when the acquiring MNE can make use of strong complementary assets. This is illustrated by point $E_{2}$ in Figure 3.2 (ii). Further, note that changes in concentration cause discontinuous upward jumps in valuations $v_{m l}$ due to the increase in concentration.

We will now use this set-up to discuss welfare effects of different policies.

\footnotetext{
${ }^{11}$ Proofs available from the authors upon request.

${ }^{12}$ Note that there also exist parameter values where an inefficient acquisition can take place and no entry occurs.
} 


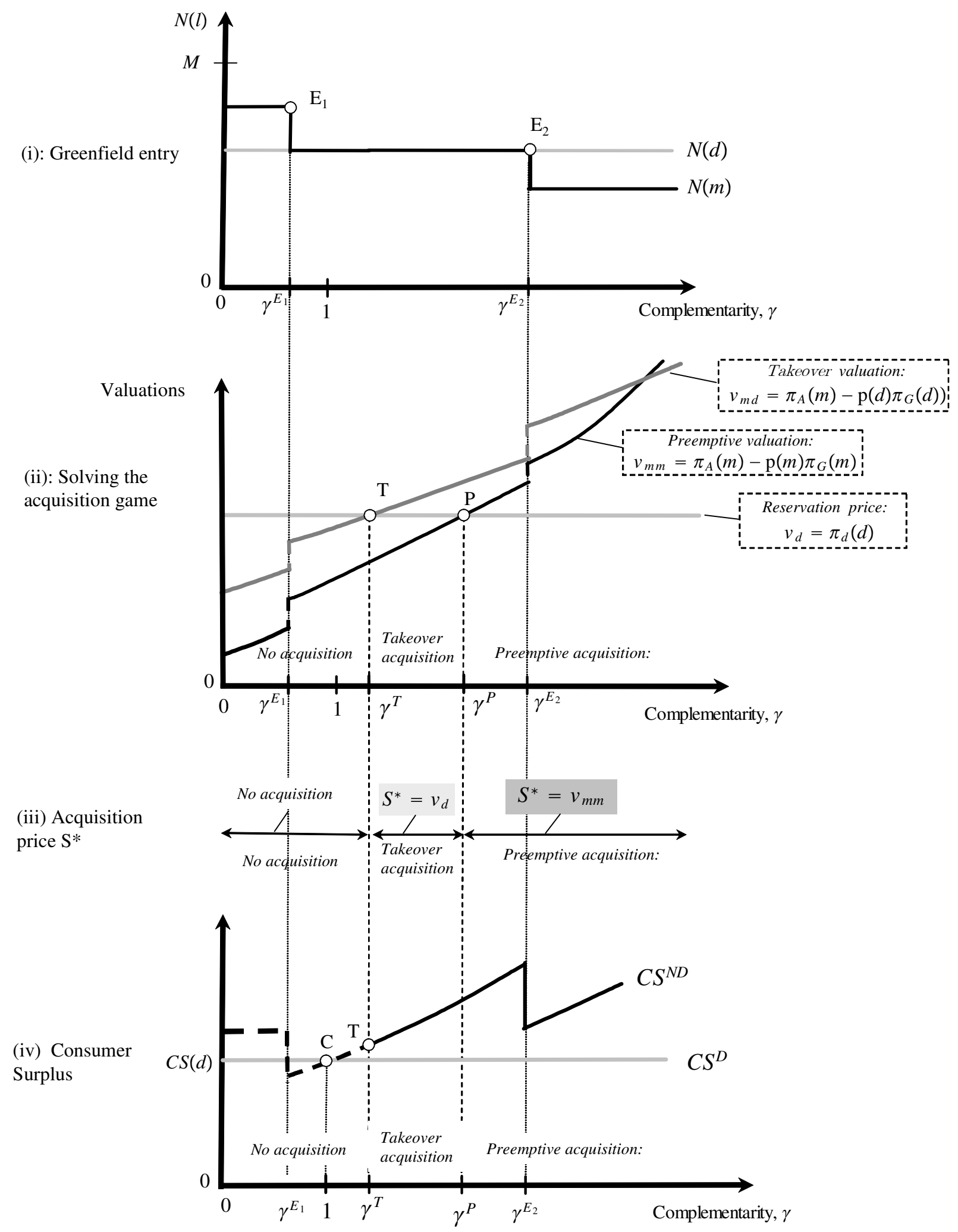

Figure 3.2: Solving the model under high entry barriers. 


\section{Cross-border M\&A policy in liberalized service markets}

In this section, we will study the impact on the host country of different policies with respect to cross-border M\&As. To this end, we assume that the domestic policy maker then commits to these policies in period 1 . We study three different policies: (i) discriminatory cross-border merger law, (ii) local equity requirements and (iii) foreign takeover regulations.

\subsection{Discriminatory cross-border merger law}

We will here compare a merger law which discriminates against foreign acquisitions to a law without such discrimination. To this end, we compare two stylized laws, which are set in period 1:

- A discriminatory law (D-law) which allows greenfield investments but not crossborder M\&As.

- A non-discriminatory law (ND-law) which allows both greenfield investments and cross-border M\&As.

Note that the $N D$ - and $D$-laws only differ when an MNE acquires the domestic assets $k_{0}$ under the $N D$-law.

To measure the welfare effects of these different laws, we let $P S(l)$ and $C S(l)$ denote the producer and consumer surplus when the ownership of $k_{0}$ is either domestic $(l=d)$ or multinational $(l=m)$. Welfare under ownership $l$ will then be the sum of the producer and consumer surplus, $W(l)=P S(l)+C S(l)$. Defining the difference in welfare between the two laws $W^{N D-D}=W(m)-W(d)$, and rearranging terms, we obtain:

$$
W^{N D-D}=\left[S^{*}-v_{d}\right]+[C S(m)-C S(d)]
$$

if an acquisition occurs under the ND-law. Note that the first term in (4.1) captures the difference in producer surplus, i.e. the sales premium, and the second term captures the 
difference in consumer surplus between the two laws. Note that $C S(m)$ can differ from $C S(d)$ for two reasons. First, a foreign and a domestic owner will make use of the domestic assets to different degrees of efficiency. Second, the number of firms active in the market might differ between domestic and foreign ownership of the domestic assets.

\subsubsection{Low entry barriers}

Let us now use the graphical framework to examine the welfare effects of the pattern of cross-border acquisition. Figure 3.1 (i) shows that takeover acquisitions can occur for complementarities below unity, i.e. where $\gamma$ is above the threshold $\gamma^{T}$ but below one. Such acquisitions lead to decreased consumer prices for two reasons: First, productivity in the acquired firm decreases, which will lead to an increase in equilibrium consumer prices. Second, the foreign acquisition leads to a market concentration, which induces an additional consumer price decrease. The aggregate effect is illustrated in the lower panel in Figure 3.1(iv) as a discrete change downwards in the consumer surplus at point $T$ in the $C S^{N D}$-locus. Thus, we note that consumers may gain if the government applies the discriminatory law in this region. However, as shown above, for the acquisition to take place, the MNE must be sufficiently efficient when using the domestic assets. Consequently the negative effect on consumers cannot be too large.

The domestic shareholders will not lose from an acquisition, however, since the foreign acquirer will pay the reservation price of the domestic seller, i.e. $S^{*}=v_{d}$.

What then occurs if there are large complementarities due to a change of ownership? A first effect is that the assets of the domestic firm will be used more efficiently. With lower production costs, the acquired firm can compete more aggressively, which leads to lower consumer prices. This is also illustrated in Figure 3.1(iii) by the fact that the consumer surplus upon an acquisition $C S^{N D}$ will increase with the complementarity, $\gamma$. At some point $C$, the efficiency gains through a high productivity in the merged firm will outweigh the increased concentration that the acquisition entails, whereby consumers will gain from foreign acquisitions being permitted. For consumers, the ND-law not only 
allowing direct investments through greenfield entry, but also through foreign acquisitions, would be preferable.

Moreover, shareholders will now gain from selling, since foreign acquirers are willing to pay more than the shareholders' reservation price. This is illustrated by the preemptive valuation of the foreign firms $v_{m m}$ being larger than the reservation price $v_{d}$ in the region beyond threshold $\gamma^{P}$, where there are large complementarities. Indeed, for sufficiently high complementarities, the domestic producer surplus increases substantially. To see this, differentiate the sales premium in (4.1) in the complementarity parameter $\gamma$ :

$$
\frac{d\left(S^{*}-v_{d}\right)}{d \gamma}=\frac{d \pi_{A}(m)}{d \gamma}-\frac{d \pi_{G}(m)}{d \gamma}>\frac{d \pi_{A}(m)}{d \gamma}>0
$$

The sales premium, i.e. the sales price net of the domestic profit under the restrictive law, is thus increasing in $\gamma$ for two reasons: First, the profit for the acquirer $\pi_{A}(m)$ increases in $\gamma$ (the asset complementarity effect), which increases the acquisition price. Second, the profit of a non-acquirer $\pi_{G}(m)$ decreases in $\gamma$ (the preemption effect), since the nonacquirer will then face a stronger competitor in the service market. This implies that the willingness to pay - and thus the acquisition price - increases even further.

\subsubsection{High entry barriers}

Now, turn to the case with high entry barriers where not all MNEs can enter the market. To examine the welfare effects of foreign acquisition on the investment pattern when entry effects are present, we use Figure 3.2. As noted in Section 3.3.2, if cross-border acquisition at low complementarities induces greenfield entry, cross-border M\&As are always associated with synergies, i.e. $\gamma^{T}>1$. Thus, as shown in Figure 3.2 (iii) and (iv), for $\gamma>\gamma^{T}>\gamma^{E_{1}}$, a foreign acquisition will increase domestic welfare since consumers will gain from a more efficient production, while the domestic shareholders receive at least their reservation price. However, Figure 3.2 (i) also shows that when complementarities increase even beyond $\gamma^{E_{2}}$, there will be less greenfield entrants that can profitably enter the market due to tough competition from the acquiring MNE. From the concentration 
effect, this implies that the consumer surplus will decrease discretely. However, shareholders might benefit from stronger bidding competition among MNEs to avoid more risky entry through greenfield investments.

In summary, we have shown that foreign acquisitions can increase the welfare of a host country if the complementarity effects upon foreign acquisitions are sufficiently large, due to (i) the increased productivity in the merged firm tending to be turned into lower consumer prices, and (ii) the bidding competition which occurs between several multinational firms and leads to the selling domestic firm getting a large share of the surplus generated by the acquisition.

But the analysis also shows that there can be anti-competitive foreign acquisitions. However, we also show that there is a limit to the possibility of market power driven cross-border M\&As, since they may trigger greenfield entry and expansion by rival firms.

\subsection{Local Equity Requirement}

The above results suggest that allowing cross-border acquisitions often raises domestic welfare and forbidding such acquisitions can be counterproductive. But other types of policies might be relevant alternatives. In practice, we observe that countries use different types of restrictions on foreign acquisitions of domestic firms. For instance, investment requirements may be applied. In other cases, countries require that a share of the new merged firm must be owned by domestic owners. ${ }^{13}$ A crucial ingredient in these policies is that they reduce the profit of the acquiring firm and increase the rents for domestic owners. To illustrate the effects of such special requirement policies, we assume that the domestic country uses a local equity requirement (LER) where the government retains an $\alpha$ share of the foreign firm's profit when acquiring the domestic firm $\pi_{A}(m)$. To focus on the effects of LER on the efficiency of cross-border M\&As, we assume there to be no LER on profits generated through greenfield entry $\pi_{G}(m)$.

Let us start with the effects of an LER-policy on domestic welfare when a takeover

\footnotetext{
${ }^{13}$ See World Investment Report (2004).
} 
acquisition takes place at price $S^{*}$ equal to the reservation price $v_{d}$, i.e. assume that we are in the region where $\gamma$ is between thresholds $\gamma^{T}$ and $\gamma^{P}$. Domestic welfare then becomes:

$$
W^{L E R}=C S(m)+v_{d}+\alpha \pi_{A}(m)
$$

A small increase in LER within this region then implies an increase in domestic rents, since the government captures a share $\alpha$ of the foreign firm's profit $\pi_{A}(m)$, while the acquisition price is unaffected since it is determined by the domestic firm's reservation price $v_{d}$. Furthermore, the consumer surplus is unaffected, since the LER level, by assumption, does not affect the service market interaction in this interval. It follows from (4.3) that the LER-policy then increases domestic welfare as compared to the case without a LER.

However, the LER may also affect the acquisition pattern and the acquisition price. To see this, note that the LER will affect both valuations $v_{m d}$ and $v_{m m}$, which can now be written:

$$
\begin{aligned}
& v_{m m}^{L E R}=(1-\alpha) \pi_{A}(m)-\left[\pi_{G}(m)-G\right] \\
& v_{m d}^{L E R}=(1-\alpha) \pi_{A}(m)-\left[\pi_{G}(d)-G\right] .
\end{aligned}
$$

It follows that both the $v_{m d}$ and the $v_{m m}$ decrease when an LER is introduced. This implies that less cross-border acquisitions will take place in equilibrium. This may increase as well as decrease domestic welfare depending on the level of $\alpha$ and $\gamma$, since both welfare-reducing (takeover) acquisitions and welfare increasing (preemptive) cross-border acquisitions can be prevented. ${ }^{14}$

In summary, we have thus shown that for a given ownership structure, imposing special requirements on cross-border M\&As increases domestic welfare, since the benefits from the special requirement are obtained without any associated cost. For high levels of complementarities between foreign and domestic assets, imposed special requirements on cross-border M\&As can, on the other hand, decrease domestic welfare by making welfare enhancing cross-border acquisitions unprofitable.

\footnotetext{
${ }^{14}$ See Norbäck and Persson (2005) for a more general treatment of this issue.
} 


\subsection{Foreign takeover regulations}

As noted in the Introduction, the EU Commission argues that cross-border mergers and acquisitions are prevented in the financial sector in the EU due to different national restrictions and specific rules. If adopting these regulations is sufficiently costly for foreign owners, it might prevent them from participating in the bidding competition over domestic target firms. Moreover, in privatizations, some countries are observed to favor specific buyers, or exclude certain other buyers from participating in the bidding competition of the privatized firm.

To capture effects of such regulations in a simple way, we assume that the different MNEs face different fixed regulation costs, $\tau_{i}$. To highlight the negative effect of such entry regulations, we here study a case where these costs are such that only one MNE will be a potential buyer, facing regulatory $\operatorname{costs} \tau$. To this end, consider the following modified set-up: There are $Z$ symmetric domestic firms for sale, $d_{1}, d_{2}, . . d_{Z}$, and only one MNE, $m_{1}$, in the market. In the acquisition game, there are three valuations to consider:

$$
\begin{aligned}
v_{d d} & =\pi_{d}(d) \\
v_{d m} & =\pi_{d}(m) \\
v_{m} & =\pi_{A}(m)-\tau-\pi_{G}(d) .
\end{aligned}
$$

Inspecting (4.6)-(4.8), we note that (4.8) is the value for the MNE entering by an acquisition instead of entering greenfield. The reservation price for a domestic firm is more complicated here and will depend on whether a rival domestic firm sells its assets. $v_{d d}=\pi_{d}(d)$ in (4.6) is the value for a domestic firm of keeping its assets when there is no sale by a rival to the MNE, whereas $v_{d m}=\pi_{d}(m)$ in (4.7) is the value for a domestic firm of keeping its assets if another domestic firm sells its assets to the MNE.

To focus on the selling competition among domestic firms as the determinant of the equilibrium ownership structure, we assume that each domestic firm $i$ announces a selling bid, $r_{i}$, for selling its respective firm. $r=\left(r_{d_{1}}, r_{d_{2}}, \ldots, r_{d_{Z}}\right) \in R^{Z}$ is the vector of these bids. 
Following the announcement of $r$, one of the bids of the domestic firm might be accepted by the MNE or no acquisition takes place.

We present a graphical solution to the game in Figure 4.1 (i). It can be shown that the properties of the figure are valid in the LQC model ${ }^{15}$. When complementarities are low $\gamma \in\left(0, \gamma^{N C}\right)$, a domestic firm has no incentive to sell as the MNE's valuation is too low, i.e. $v_{m}<v_{d d}<v_{d m}$.

However, at increasing complementarities, the MNE's valuation increases and, at some point, $\gamma=\gamma^{N C}, v_{m}=v_{d d}<v_{d m}$. This implies that an acquisition takes place. In this region $\gamma \in\left[\gamma^{N C}, \gamma^{C}\right)$, a domestic firm will offer the MNE to buy at a price $v_{m}$, which will be accepted by the MNE. We may consider a sale of a domestic firm to the MNE in this region as noncompetitive (NC).

At even larger complementarities, $\gamma \geq \gamma^{C}$, the acquiring MNE now becomes a very efficient rival. This initiates a seller competition among domestic firms and a sale of a domestic firm in this region may be considered as competitive (C). Since $v_{m}>v_{d m}$ holds in this region, a selling bid at $v_{m}$ cannot be an equilibrium, since domestic rivals would then gain from undercutting. The seller competition among domestic firms then drives down the equilibrium offer to $v_{d m}$. Hence, the EOS is $K(m)$ and $S^{*}=v_{d m}$. This equilibrium is illustrated in the interval $\gamma \geq \gamma^{C}$ in Figures 4.1 (i) and (ii).

Figure 4.1 (iii) then depicts how the target firm's rents or surplus depend on the level of complementarities $\gamma, R(l)$. The rent under domestic ownership is simply $R(d)=v_{d d}=$ $\pi_{d}(d)$, whereas the target firm's rents from a sale is given given from:

$$
R(m)=\left\{\begin{array}{rr}
v_{m}=\pi_{A}(m)-\tau-\pi_{G}(d), & \gamma \in\left[\gamma^{N C}, \gamma^{C}\right) \\
v_{d m}=\pi_{d}(m) & \gamma \geq \gamma^{C}
\end{array}\right.
$$

Using the no cross-border acquisition as a benchmark, the figure illustrates that for low complementarities, the target firm's surplus increases when an acquisition takes place. However, Figure 4.1 (iii) also illustrates that for sufficiently high complementarities, $\gamma^{R}$, the target firm's surplus will be lower when an acquisition takes place. The reason is

\footnotetext{
${ }^{15}$ Proofs available from the authors upon request.
} 
(i): Solving the acquisition game (iii) Producer surplus

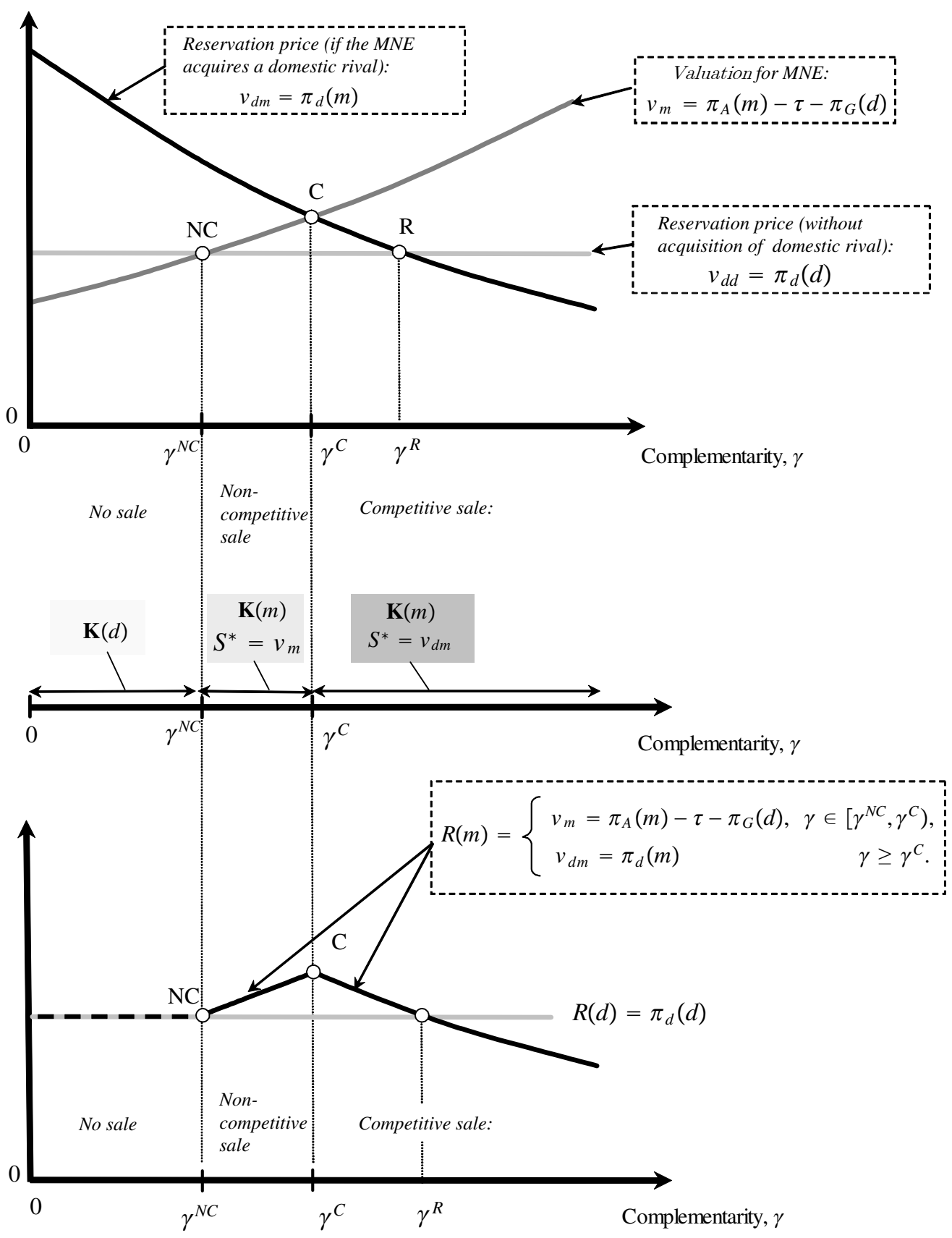

Figure 4.1: Solving the model under seller competition. 
that the sales price is then below the profit the domestic target firm would generate absent the acquisition. Note that there will also be effects on the domestic rivals' profits. The acquisition will increase their profits due to the concentration effect. However, at sufficiently high complementarities, the acquiring firm will become so efficient that it will produce at such high levels that consumer prices become so low that the rival firms' profits decrease.

In summary, we have thus shown that foreign acquisitions are still more likely when domestic and foreign assets become more complementary, also when there is seller competition. However, the gains from an acquisition at high complementarities accrue to the foreign acquirer, in fact leaving domestic firms worse off. Consequently, ensuring bidding competition over domestic firms is crucial for generating a high producer surplus in foreign acquisitions. Having policies which give the many potential buyers the opportunity to participate in the acquisition market therefore seems warranted. This seems particularly relevant for the case of privatizations.

\section{Domestic merger policy in liberalized service markets}

An important ingredient in many of the liberalization programs of the service sector has been to allow foreign firms to enter these markets in order to create more competitive market structures. However, there is a concern that many of these liberalizations have not been successful in this respect. For instance, the EU has documented severe obstacles to greenfield investments in the service sector. If cross-border acquisitions are possible, however, the problem might be mitigated since efficient foreign firms could then enter by means of acquisitions. But, in these situations, domestic firms might protect their markets by means of preemptive domestic acquisitions.

To illustrate this effect, we modify the base model in the following way. We maintain the assumption of several symmetric foreign firms but now assume that there are initially two domestic firms present in the market where one is for sale. This could be due to the 


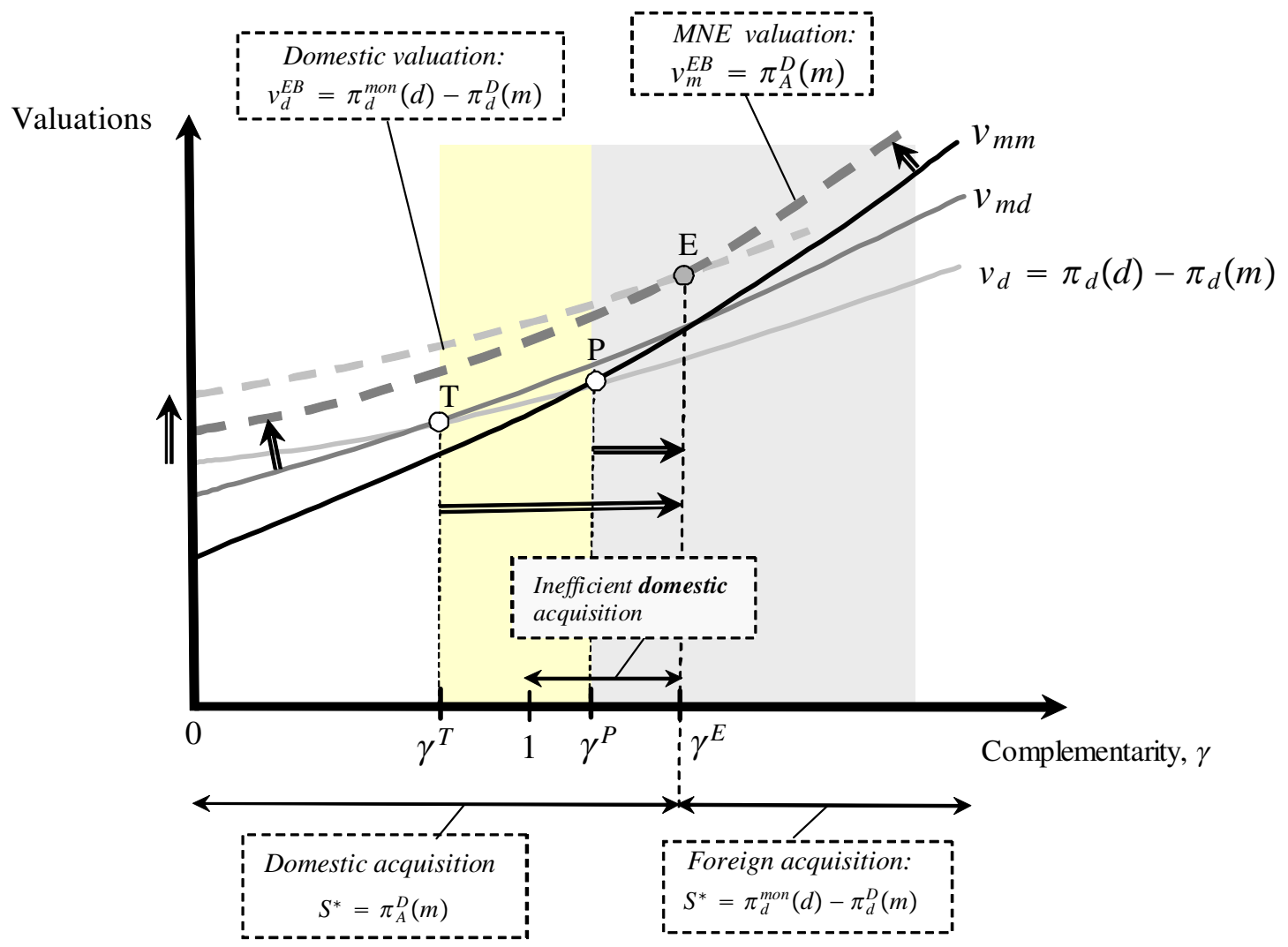

Figure 5.1: Illustrating preemptive domestic acquisitions 
privatization of a state enterprise or due to bad management practises warranting a sale of the firm, for instance. Then, we can reinterpret $v_{d}$ as the domestic rival firm's value of obtaining the domestic firm for sale (assuming that the reservation price for the domestic firm for sale is zero). MNEs' valuations $v_{m d}$ and $v_{m m}$ do not change. However, $v_{d}$ now becomes:

$$
v_{d}=\pi_{d}(d)-\pi_{d}(m)
$$

If we now introduce entry barriers (EB) effectively shutting down greenfield entry with high greenfield costs, i.e. assuming that entry cost $G$ is higher than the profit from greenfield entry $\pi_{G}(l)$, valuations now become:

$$
\begin{aligned}
& v_{m}^{E B}=\pi_{A}^{D}(m) \\
& v_{d}^{E B}=\pi_{d}^{m o n}(d)-\pi_{d}^{D}(m),
\end{aligned}
$$

since the market structure is either a domestic monopoly with firm $d$ making the profit $\pi_{d}^{m o n}(d)$ or the market structure is a duopoly with the foreign acquirer having the profit $\pi_{A}^{D}(m)$ and the domestic rival having the profits $\pi_{d}^{D}(m)$.

The equilibrium is presented in Figure 5.1. It can be shown that the figure is valid in the LQC model ${ }^{16}$. Note from (3.7) and (3.6) that the foreign firms' valuation of acquiring the domestic firm increases when the greenfield cost $G$ increases. This follows from the fact that the second term in $v_{m m}$ and $v_{m d}$ decreases when the greenfield cost $G$ increases. As long as the increase in the greenfield cost $G$ does not affect the greenfield entry pattern, $v_{d}$ is unchanged since the market structure is not affected, but only the profits of greenfield entrants. However, at a sufficiently high greenfield cost, $G$, greenfield entry will not be possible. Then, firms' valuations are given by (5.1)-(5.3), where we note that since greenfield entry is not profitable, MNEs have a single valuation, $v_{m}^{E B}=\pi_{A}^{D}(m)$. It can then be shown that the domestic firm can prevent entry by acquiring the domestic firm for sale, i.e. undertaking a so-called preemptive acquisition. This is shown in Figure 5.1

\footnotetext{
${ }^{16}$ Proofs available from the authors upon request.
} 
where $v_{d}$ is shifting upwards to $v_{d}^{E B}$. Note that if $\gamma$ is between one and the threshold $\gamma^{E}$, an inefficient domestic acquisition occurs, i.e. the domestic firm makes the acquisition despite the fact that it will use the assets less efficiently. ${ }^{17}$

In summary, we have thus shown that for sufficiently high greenfield costs and sufficiently concentrated service markets, preemptive domestic acquisitions will take place, i.e. domestic acquisitions motivated by the desire to prevent a cross-border acquisition. Thus, it is important to ensure that the greenfield costs are kept down also when cross-border acquisitions are possible. As shown by Campa et al (1998), domestic firms also have an incentive to raise the entry barriers in these situations. This would correspond to a situation where domestic firms could invest in increasing the greenfield cost of the foreign firm, which in our framework would shift the $v_{m d}$ and $v_{m m}$ curve up to $v_{m}^{E B}$ but possibly also the $v_{d}$ curve up even more to $v_{d}^{E B}$. If the cost of this entry deterring activity is sufficiently low, the domestic firms will undertake it with the consequence of not only blocking greenfield entry but also inducing preemptive domestic acquisitions. Consequently, competition authorities have an important task in monitoring these behaviors and considering preemptive acquisitions. These aspects seem particularly relevant in newly liberalized service markets, since domestic incumbent firms are likely to have initial advantage in such markets.

\section{Conclusions}

In this paper, we have provided facts showing that in service markets: (i) restrictions on foreign direct investment are under reform, (ii) cross-border Mergers \& Acquisitions are sizable, and (iii) have a high concentration level. Based on these facts, we have developed a model suitable for analyzing cross-border M\&A policy, taking into account efficiency and market power effects, and where a graphical solution to the model is presented. Our findings suggest that a merger policy, but not a discriminatory policy towards foreigners,

\footnotetext{
${ }^{17}$ See Bjorvatn (2004), Horn and Persson (2001) and Norbäck and Persson (2004) for a more general treatment of the pattern of domestic and cross-border M\&As.
} 
seems warranted. Moreover, policies ensuring competition for domestic target firms also seem warranted.

In the analysis, we have studied effects of stylized policies such as effects of allowing and forbidding cross-border M\&A, and effects of increasing the cost of foreign takeovers. Even though these stylized policies abstract from important features of policy in practice, we believe that these exercises capture important effects of these policies that should be taken into account. The complexity of the externalities involved in the mergers and investments indicates that informational constraint will be important for deriving optimal policies. An interesting step is then to explicitly model this restriction and investigate whether policies resulting in a higher welfare level might be found.

Moreover, we have abstracted from the allocation of jurisdiction in the merger control. Should a merger proposal be reviewed at the level of a supra-national competition authority or by a national competition authority? In the model, cross-border M\&As are associated with externalities on both domestic and foreign citizens. Consequently, the national optimal decision will not correspond to the optimal one for all countries. However, the complexity of the externalities involved in the merger formation indicates that informational and political constraint will be important for deriving optimal policies also in this respect. A interesting step is then to explicitly model this restriction and investigate how the jurisdiction should be allocated.

\section{References}

[1] Barba Navaretti, G. and A. Venables. 2004. Multinational firms in the world economy. Princeton University Press, Princeton and Oxford.

[2] Bjorvatn, K., 2004, "Economic integration and the profitability of cross-border mergers and acquisitions," European Economic Review, Volume 48, Issue 6, 1211-1226. 
[3] Campa, J., S. Donnenfeld and S. Weber, 1998, "Market structure and foreign direct investment," Review of International Economics, 6(3), 361-380.

[4] Falvey, R., 1998, "Mergers in open economies," The World Economy, 21, 1061-1076.

[5] Head K, and J. Reis, 1997, "International Mergers and Welfare under Decentralized Competition Policy", Canadian Journal of Economics, v30, n4: 1104-23.

[6] Heyman F., F. Sjöholm, and P.G. Tingvall, 2007, "Is there Really a Foreign Ownership Wage Premium? Evidence from Matched Employer-Employee Data", Journal of International Economics, Vol. 73, No. 2.

[7] Horn, H. and L. Persson, 2001, "The Equilibrium Ownership of an International Oligopoly," Journal of International Economics, Vol. 53, No. 2.

[8] Klimenko M. and K. Saggi, 2007, "Technical compatibility and the mode of foreign entry with network externalities," Canadian Journal of Economics, 40, 176-206.

[9] Lommerud, K.E., O. R. Straume and L. Sorgard, 2006, "National versus international mergers in unionized oligopoly," RAND Journal of Economics, 37, 212-233.

[10] Markusen, J. R., 1995, "The Boundaries of Multinational Enterprises and the Theory of International Trade," Journal of Economic Perspective 9, 169-189.

[11] Mattoo A., Olarrega M., and K. Saggi , 2004, "Mode of foreign entry, technology transfers, and FDI policy," Journal of Development Economics, 75, 95-111.

[12] Neary, J. P., 2007, "Cross-border mergers as instruments of comparative advantage," Review of Economic Studies, 74:4, 1229-1257.

[13] Nocke, V. and S. Yeaple, 2007, "Cross-border Mergers and Acquisitions versus Greenfield Foreign Direct Investment: The Role of Firm Heterogeneity," Journal of International Economics, Vol. 72, No. 2, 336-365. 
[14] Norbäck, P. J. and L. Persson, 2004, "Privatization and Foreign Competition," Journal of International Economics,62, 409-416.

[15] Norbäck, P-J. and L. Persson. 2005, "Privatization policy in an international oligopoly," Economica, 72(288), 635-653.

[16] Norbäck, P-J. and L. Persson. 2006, "Endogenous Asset Ownership Structures in Deregulated Markets", European Economic Review, Vol. 50, No.7, 1729-52.

[17] Norbäck, P. J. and 1. Persson, 2007, "Investment Liberalization - Why a Restrictive Cross-Border Merger Policy can be Counterproductive", Journal of International Economics, Vol. 72, No. 2, 366-380.

[18] OECD. 2006. International Investment Perspectives. 2006 Edition.

[19] Saggi, K. and H.M. Yildiz, 2006, "On the international linkages between trade and merger policies", Review of International Economics, 14(2), 212-225.

[20] Straume, O.R., 2003, "International mergers and trade liberalization: implications for unionized labour," International Journal of Industrial Organization, 21, 717-735.

[21] UNCTAD, World Investment Report 2000, (United Nations Conference on Trade and Development, Geneva). 


\section{A. Appendix: The Linear-Quadratic Cournot Model}

In the Linear-Quadratic Cournot model, we capture that different types of investment have different effects on firms' production costs, which allows to us derive explicit solutions for the optimal behavior by firms in all stages of the game, and characterize welfare effects. We model the oligopoly interaction in period three as Cournot competition in homogenous services. Investments in new assets in period two reduce the firm's marginal cost. The profit for firm $i$ can be written:

$$
\pi_{i}(\mathbf{q}, \boldsymbol{\kappa}, l)=R_{i}(\mathbf{q}, \boldsymbol{\kappa}, l)-\frac{\mu \kappa_{i}^{2}}{2}-G_{i}
$$

where $R_{i}=\left(P-c_{i}\right) q_{i}$ is the service market profit and we assume costs to be quadratic in new assets, $\kappa_{i}$. Firms face the inverse demand $P=a-\frac{1}{s} \sum_{i=1}^{N} q_{i}$, where $a>0$ is a demand parameter, $s$ may be interpreted as the size of the market and $N$ is the total number of firms in the market. Investments in new capital reduce a firm's marginal cost in a linear fashion $c_{i}=\bar{c}_{i}-\theta \kappa_{i}$, where $\theta$ is a positive constant measuring how effectively investments in new capital $\kappa_{i}$ in stage two reduce the marginal cost. For simplicity, we assume that all firms share the same investment technology, $\theta$ and $\mu$. Asymmetries between firms are captured by the intercept term, $\bar{c}_{i}$, which measures the impact on firm $i$ 's absolute efficiency level of the possession of all other assets prior to investment in new assets, $\kappa_{i}$, in stage 2. Making a distinction between firm types, we have:

$$
\bar{c}_{G}=c, \quad \bar{c}_{A}=c+\tilde{c}_{A}-\gamma \bar{k}, \quad \bar{c}_{d}=c+\tilde{c}_{d}-\bar{k}
$$

Hence, we assume existing assets $\bar{k}$ and new assets $\kappa_{i}$ to be imperfect substitutes. The complementarity parameter $\gamma$ again shows the effect of adding foreign firms' firm-specific assets to domestic assets $k_{0}$. Similarly, we capture other cost asymmetries by including $\tilde{c}_{A}$ and $\tilde{c}_{d}$.

From (3.2), $\frac{\partial R_{i}}{\partial q_{i}}=P-c_{i}-q_{i}=0$ from which optimal quantities $q^{*}(\kappa, l)$ are derived. In stage two, (3.3) implies that $\frac{d \pi_{i}}{d \kappa_{i}}=\frac{\partial R_{i}}{\partial \kappa_{i}}+\sum_{j \neq i}^{T} \frac{\partial R_{i}}{\partial q_{j}} \frac{d q_{j}}{d \kappa_{i}}-F_{i}^{\prime}=0$, where optimal investments are given from $\kappa_{i}^{*}(l)=\frac{\theta}{\mu} q_{i}^{*} \frac{2 N}{N+1}$. Solving for stage 2 investments $\kappa^{*}(l)$ and stage 3 sales 
$q^{*}(l)$, we have the reduced-form profits $\pi_{i}(l)$. It can be shown that these profits take the form $\pi_{i}(q, \kappa, l)-\frac{\mu \kappa_{i}^{2}}{2}=\frac{1}{s}\left(q_{i}^{*}(l)\right)^{2}\left[1-\frac{2 \eta}{9}\right]-G_{i}$, where $\eta=s \frac{\theta^{2}}{\mu}$. Table A.1 gives the explicit expression for the LQC model. Finally, Figure A.1 shows a numerical solution of the model given in Section 3.3.1.

Table A.1: Equilibriium quantities and profits as functions of ownership structure.

\begin{tabular}{|c|c|c|}
\hline & Domestic ownership & Foreign ownership \\
\hline$l:$ & $d$ & $m$ \\
\hline$\pi_{h}(l):$ & $\frac{1}{s} q_{h}^{2}(d)\left[1-\frac{2 \eta}{9}\right]$ & $\frac{1}{s} q_{h}^{2}(m)\left[1-\frac{2 \eta}{9}\right]$ \\
\hline$q_{A}(l):$ & & $\frac{s(N(m)+1)\left[\Lambda(1+N(m)-2 N(m) \eta)-N(m) \hat{c}_{A}(1+N(m)-2 \eta)\right]}{(1+N(m)-2 N(m) \eta)\left(1+2 N(m)+N^{2}(m)-2 N(m) \eta\right)}$ \\
\hline$q_{G}(l):$ & $\frac{s(N(d)+1)\left[\Lambda(1+N(d)-2 N(d) \eta)+\hat{c}_{d}(N(d)+1)\right]}{(1+N(d)-2 N(d) \eta)\left(1+2 N(d)+N^{2}(d)-2 N(d) \eta\right)}$ & $\frac{s(N(m)+1)\left[\Lambda(1+N(m)-2 N(m) \eta)+\hat{c}_{A}(N(m)+1)\right]}{(1+N(m)-2 N(m) \eta)\left(1+2 N(m)+N^{2}(m)-2 N(m) \eta\right)}$ \\
\hline$q_{d}(l):$ & $\frac{s(N(d)+1)\left[\Lambda(1+N(d)-2 N(d) \eta)-N(d) \hat{c}_{d}(1+N(d)-2 \eta)\right]}{(1+N(d)-2 N(d) \eta)\left(1+2 N(d)+N^{2}(d)-2 N(d) \eta\right)}$ & \\
\hline Note: & $\eta \equiv \frac{s \theta^{2}}{\gamma}, \quad \Lambda \equiv a-c, \hat{c}_{A} \equiv \tilde{c}_{A}-\gamma \bar{k}$ & $\hat{c}_{d} \equiv \tilde{c}_{d}-\bar{k}$ \\
\hline
\end{tabular}




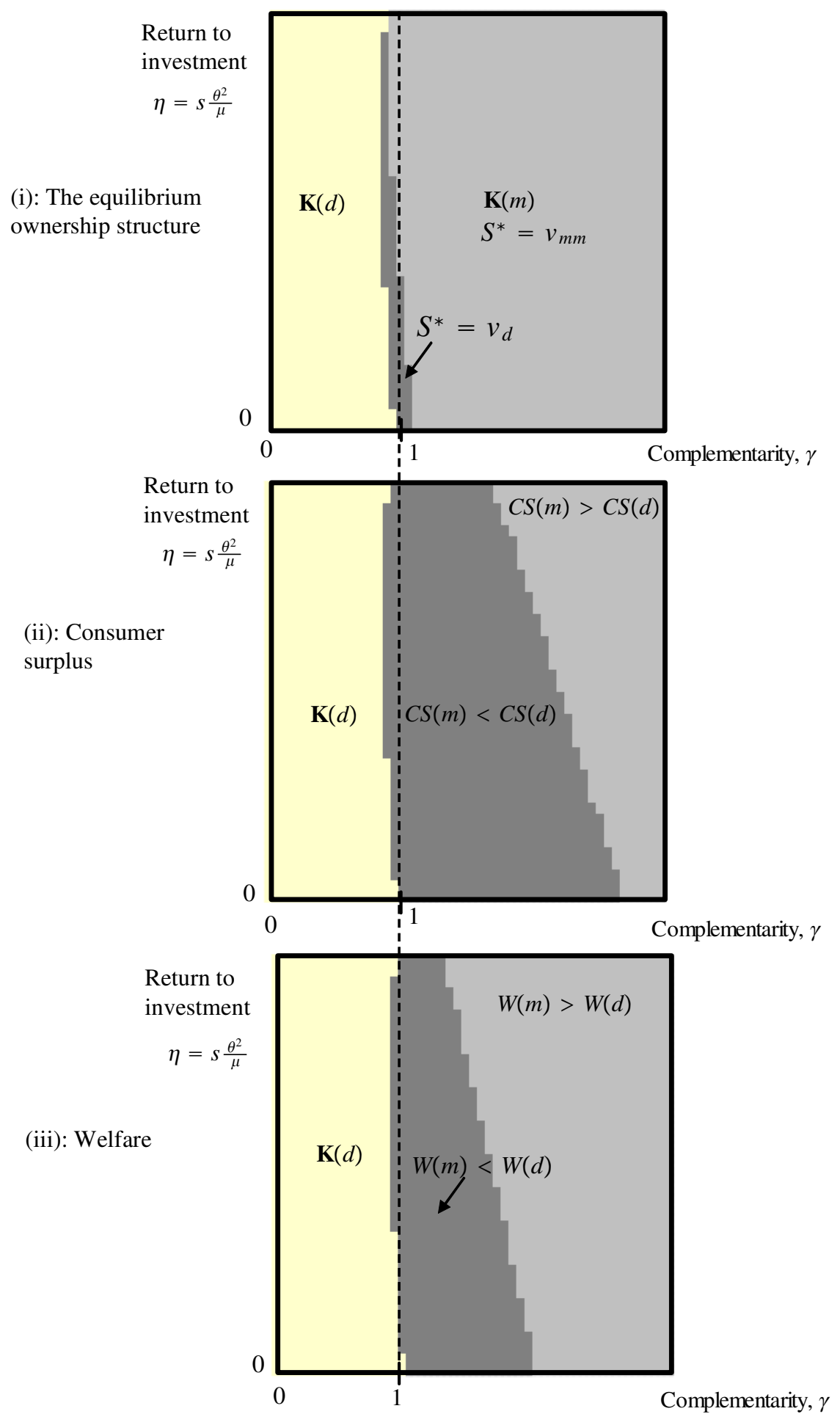

Figure A.1: Numerical solution in the Linear-Quadratic Cournot model for the case of low entry barriers in Section 3.3.1. Parameter values at $G_{G}=0.1, G_{A}=G_{E}=0, \bar{k}=1, \Lambda=$ $s=5, M=4$ and $\tilde{c}_{A}=\tilde{c}_{d}=0$. 